\title{
Effects of a Walking Program on Self-management and Risk Factors of Metabolic Syndrome in Older Korean Adults
}

\author{
Eun-Gyoung Lee, RN, Community Health Practitioner ${ }^{1)}$, Jung-Hyun Choi, RN, PhD²*, \\ Kyoung-Eun Kim, $\mathrm{PhD}^{3)}$, Jee- Hee Kim, MD, PhD ${ }^{4}$ \\ 1) Sangpyung Public Health Center, Republic of Korea \\ 2) Department of Nursing, Namseoul University: 21 Maeju-ri, Sungwan-eup, Seobuk-Gu, Chonan-Si \\ 331-707, Republic of Korea \\ 3) Department of Child Welfare, Namseoul University, Republic of Korea \\ 4) Department of Emergency Medical Technology, Kangwon National University, Republic of Korea
}

\begin{abstract}
Purpose] The aim of this study was to determine the effects of a 12-week walking program on increasing an individual's self-management and decreasing the risk factors of metabolic syndrome in the older adult population. [Subjects] A total of 31 older adults participated in this study. Eighteen participants in the experimental group and 13 controls completed the pretest and posttest measures. A walking exercise and health education were provided for the experimental group. Data were analyzed by ANCOVAs to examine group differences. [Results] At the end of the 12-week study period, the experimental group showed a significant improvement in individuals' ability to self-manage their health compared to the control group. Also, there were significant differences between the two groups in the total numbers of risk factors of metabolic syndrome, systolic blood pressure and BMI. No significant difference in blood sugar levels, HDL-C, waist circumference, and triglyceride levels were found between the experimental and control group. [Conclusion] This study revealed that a combination of health education and for walking exercise can lead to improved lifestyle management and reduce risk factors of metabolic syndrome for the elderly population of Korea.

Key words: Metabolic syndrome, Walking program, Older adults
\end{abstract}

(This article was submitted Jul. 8, 2013, and was accepted Aug. 12, 2013)

\section{INTRODUCTION}

Metabolic syndrome is a collection of symptoms that leads to increased risk of cardiovascular disease and diabetes. Each risk factor, on its own, may not cause significant health issues, but a combination of these risk factors may lead to serious health implications for an individual. The Framingham Offspring Study showed that metabolic syndrome contributed to almost half of the population-attributable risk of diabetes, and approximately a quarter of all incidents of cardiovascular disease ${ }^{1)}$.

The incidence of metabolic syndrome is rapidly increasing in people over the age of $60^{2}$. Metabolic syndrome appears to affect approximately 10 to $25 \%$ of adult populations worldwide ${ }^{3)}$. Analysis of data of 6,423 adult men and nonpregnant women, from the Third National Health and Nutrition Examination Survey (NHANES III), showed that the age-adjusted prevalence of metabolic syndrome

*Corresponding author. Jung-Hyun Choi (e-mail: jhc@nsu. ac.kr)

(C)2014 The Society of Physical Therapy Science

This is an open-access article distributed under the terms of the Creative Commons Attribution Non-Commercial No Derivatives (by-ncnd) License $<$ http://creativecommons.org/licenses/by-nc-nd/3.0/>. was $34.2 \%$ among U.S. adults, and higher prevalence of metabolic syndrome was noted with increasing age. An endeavor to prevent the increase in the number of metabolic syndrome cases among the elderly is needed.

Walking is recommended for the elderly because walking is an easy exercise to practice ${ }^{4)}$. Walking is a simple exercise, which does not require special equipment. As walking can be performed anywhere regardless of season or weather, compared with other kinds of sports, the practice rate of walking exercise was reported to be the highest for the elderly ${ }^{5}$. Walking offers the perfect combination of exercise and a feeling of immense satisfaction ${ }^{6}$, and a positive effect on body composition and lipid profiles of women aged over 65 years old ${ }^{4}$. Nuri et al. ${ }^{7}$ ) reported that supervised walking and standard resistance training program can improve metabolic syndrome parameters after 15 weeks. Their results show that walking exercise was effective at ameliorating metabolic syndrome.

Previous research has focused on exercise as the sole intervention for the elderly with metabolic syndrome ${ }^{8,9)}$. As metabolic syndrome correlates directly with obesity and sedentary lifestyles, health education for patients is of significant importance in the self-management of risk factors, such as obesity, high blood pressure, and smoking ${ }^{10)}$. Self-management is defined as the factor of self-care related 
to cognitive decision-making in reaction to patients' symptoms or signs ${ }^{11)}$, and it is a very complicated process that requires acute perception and evaluation of subtle changes in an individual's own health condition. Self-management is a term applied to educational programs aimed at teaching the skills needed to carry out medical regimens specific to a disease, guide change in behavior regarding health, and provide emotional support for patients to control their disease and increase their quality of life ${ }^{12)}$. As self-management encourages the patients to actively take part in managing their illness, patients' self-management is closely related to improved health behavior and health status ${ }^{13)}$. However, few studies of the effect of both exercise and health education on metabolic syndrome have been performed ${ }^{14)}$. Therefore, we designed a walking program composed of walking exercise and health education, and conducted walking programs for older adults with metabolic syndrome.

In Korea, the majority of studies regarding the effect of exercise on metabolic syndrome have been conducted in health centers in urban regions, and little is known regarding the rural population. In Korea, $72 \%$ of the rural population do not have access to gym facilities, fitness classes or exercise equipment ${ }^{15}$. Also, rural people have little opportunity to receive health education and counseling. Therefore, this study introduced a combination of a walking exercise and health education to rural residents to improve their self-management abilities, and to decrease risk factors of metabolic syndrome.

The aim of the study was to determine the effects of a 12-week walking exercise and health education program on self-management and risk factors of metabolic syndrome of older adults.

\section{SUBJECTS AND METHODS}

The participants were 36 older adults aged over 60 years old who volunteered to participate in the walking program at health centers (Fig. 1). The inclusion criteria were based on the presence of three or more of the following clinical criteria: $\mathrm{WC} \geq 90 \mathrm{~cm}$ for men and $\geq 80 \mathrm{~cm}$ for women; TG levels $\geq 150 \mathrm{mg} \cdot \mathrm{dL}^{-1}$; (3) HDL levels $<40 \mathrm{mg} \cdot \mathrm{dL}^{-1}$ for men or $<50 \mathrm{mg} \cdot \mathrm{dL}^{-1}$ for women; systolic blood pressure (SBP) $\geq$ $130 \mathrm{mmHg}$, or diastolic blood pressure (DBP) $\geq 85 \mathrm{mmHg}$, or the use of antihypertensive medication; fasting blood sugar $\geq 110 \mathrm{mg} \cdot \mathrm{dL}^{-1}$ or the use of anti-diabetic medication or insulin; and body mass index $\geq 25 \mathrm{~kg} / \mathrm{m}^{2}$. Metabolic syndrome was defined according to the revised National Cholesterol Education Program Adult Treatment Panel III (NCEP-ATP III) criteria.

The experimental group of 21 people was comprised of rural residents attending 2 health centers in E county. The control group of 15 people was comprised of persons attending other health centers in E county, which had similar demographic characteristics. Dropout rates in the experimental group and control groups were $14.3 \%$ and $13.3 \%$, respectively. At the end of the intervention, the experimental group contained 18 rural elderly and the control group contained 13 rural elderly. Table 1 shows the general characteristics of the subjects of this study. There were no significant differences between the two groups regarding gender, job, educational level, income, and the risk factors of metabolic syndrome. The experimental group participated in the walking program. The walking program consisted of walking exercise and health education. Walking exercise was provided three times per week for 12 weeks. Walking exercises were performed in 3 stages. Participants exercised with an instructor through stages $1-3$. Stage 1 was the initial stage where subjects walked $2-3 \mathrm{~km}$ for $30-40$ minutes, while maintaining $40 \%$ of maximum heart rate (HRmax)

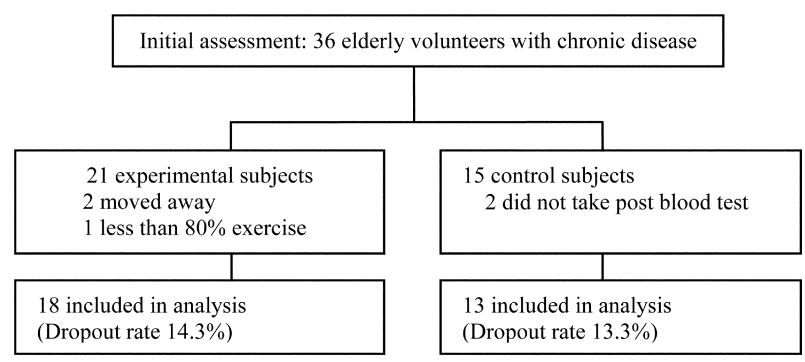

Fig. 1. Flow chart of participation selection process

Table 1. Walking exercise and health education

\begin{tabular}{llll}
\hline stage & Week & Walking exercise* (3 times a week) & Health education (12 times) \\
\hline Stage 1 & Week 1 & 2 km for 30 minutes, $40 \%$ of HRmax & Introduction of metabolic syndrome \\
& Week 2 & 3 km for 40 minutes, $\quad 40 \%$ of HRmax & Exercise and posture \\
Stage 2 & Week 3 & $4 \mathrm{~km}$ for 50 minutes, $\quad 50 \%$ of HRmax & Proper walking \\
& Week 4 & $5 \mathrm{~km}$ for 50 minutes, $\quad 60 \%$ of HRmax & Nutrition \\
Stage 3 & Week 5 & $5-6 \mathrm{~km}$ for 50 minutes, 60\% of HRmax & Alcohol \\
& Week 6 & $5-6 \mathrm{~km}$ for 50 minutes, 60\% of HRmax & Smoking \\
& Week 7 & $5-6 \mathrm{~km}$ for 50 minutes, 60\% of HRmax & Daily stressors \\
& Week 8 & $5-6 \mathrm{~km}$ for 50 minutes, 60\% of HRmax & High blood pressure \\
& Week 9 & $5-6 \mathrm{~km}$ for 50 minutes, 60\% of HRmax & High blood sugar \\
& Week 10 & $5-6 \mathrm{~km}$ for 50 minutes, 60\% of HRmax & High blood cholesterol \\
& Week 11 & $5-6 \mathrm{~km}$ for 50 minutes, 60\% of HRmax & Obesity \\
& Week 12 & $5-6 \mathrm{~km}$ for 50 minutes, 60\% of HRmax & Revision of all topics \\
\hline
\end{tabular}


in the 1st-2nd week. Stage 2 was the enhancement stage which was performed in the 3rd-4th week. Participants walked $4-5 \mathrm{~km}$ for 50 minutes, while maintaining $50 \%$ of HRmax. Stage 3 was the maintenance stage in which participants walked 5-6 km for 50 minutes, while maintaining $60 \%$ of HRmax. The times noted above exclude the warming-up and cooling-down periods. For the warm-up and cool-down sessions, participants performed stretches, and running on the spot for 5 minutes each (Table 2). The experimental group received health education and counseling once a week, regarding dietary principles and disease control. Health education focused on self-management of metabolic syndrome, including hypertension and diabetes mellitus. Health education and counseling were provided 12 times, and lasted 60 minutes per session. The mean attendance rate for the experimental group was $94.7 \%$. The control group did not participate in other health promotion programs.

Before we began collecting data, we explained the purpose of this study and received the consent of all of the participants. This study was approved by Namseoul University, and the approval number is Research-20121205. Data were collected to measure participant's general characteristics, self-management, and risk factors of metabolic syndrome. Body measurements were evaluated before and after the 12week walking program by trained research assistants, and blood tests were conducted by a researcher who was a nurse.

The participant's self-management of their health was assessed using a self-management scale ${ }^{16)}$. The self-management scale in this study was composed of 17 items, coded from 1 to 3, with 1 representing "strongly disagree", 2 representing "agree" and 3 representing "strongly agree." The items covered dietary treatment, weight control, drinking, smoking, exercise, sleep, and medication status related to essential metabolic syndrome patients' self-care. One item regarding sleeping, which is closely related to metabolic syndrome, was added in this study. The revised self-management scale was examined by three experts for content validity. Higher scores directly correlate with better selfmanagement. The reliability (Cronbach's $\alpha$ ) of the instrument was 0.72 in Lee ${ }^{16)}$ 's study and 0.91 in the present study.

Subjects' height was measured in millimeters using a portable height scale, their weight was measured to an accuracy of $100 \mathrm{~g}$ using a digital weight scale (CASS digital, Korea), and their body mass index (BMI) was calculated by dividing weight $(\mathrm{kg})$ by height squared $\left(\mathrm{m}^{2}\right)$. Participants' blood pressure was measured at the health center after a 30 minute rest on the test day. Following a 5-minute rest period, arterial blood pressure of the right arm was measured by a mercury sphygmomanometer while the subject rested in a seated position. Two measurements were taken at each time point and the mean of both the systolic (SBP) and diastolic (DBP) pressures were recorded for later analyses. The waist line was measured with a tape measure on the belly button line in a comfortable standing position. Fasting blood sugar, high density lipoprotein-cholesterol (HDL-C), and triglyceride levels were tested by collecting blood after fasting at the baseline, and at the end of the 12-week intervention.

Data were analyzed, using SPSS for Windows, v18.0. Descriptive statistics were used for demographic variables and major study variables. A homogeneity test was used to detect any significant group differences in the demographic data and pretest measures. ANCOVAs were used to examine group differences in outcome variables. The level of significance used in all statistical analyses was $\alpha=0.05$.

\section{RESULTS}

Group comparisons were made of changes in the outcome variables between pretest and posttest measures to assess the effects of the walking program. On completion

Table 2. Demographic characteristics and baseline measures of subjects by group

\begin{tabular}{|c|c|c|c|c|}
\hline \multirow{2}{*}{ Category } & \multirow{2}{*}{\multicolumn{2}{|c|}{ Item }} & Experimental $(n=18)$ & Control $(n=13)$ \\
\hline & & & $\mathrm{N}(\%)$ & $\mathrm{N}(\%)$ \\
\hline \multirow{2}{*}{ Gender } & \multicolumn{2}{|l|}{ Male } & $2(11.1)$ & $2(15.4)$ \\
\hline & \multicolumn{2}{|l|}{ Female } & $16(88.9)$ & $11(84.6)$ \\
\hline \multirow{3}{*}{ Occupation } & \multicolumn{2}{|l|}{ Farming } & $12(66.7)$ & $7(53.8)$ \\
\hline & \multicolumn{2}{|l|}{ None } & $2(11.1)$ & $1(7.7)$ \\
\hline & \multicolumn{2}{|l|}{ Housewife } & $4(22.2)$ & $5(38.5)$ \\
\hline \multirow{3}{*}{ Education level } & \multicolumn{2}{|c|}{ None (illiterate) } & $7(38.9)$ & $5(38.5)$ \\
\hline & \multicolumn{2}{|c|}{ Literate } & $1(5.6)$ & $2(15.4)$ \\
\hline & \multicolumn{2}{|c|}{ Elementary or above } & $10(55.6)$ & $6(46.2)$ \\
\hline \multirow{2}{*}{ Income } & \multirow{2}{*}{\multicolumn{2}{|c|}{$\begin{array}{l}\text { Less than } 1 \text { million (won) } \\
\text { More than } 1 \text { million (won) }\end{array}$}} & $12(66.7)$ & $10(76.9)$ \\
\hline & & & $6(33.3)$ & $3(23.1)$ \\
\hline \multirow{6}{*}{ Disease } & \multirow{2}{*}{$\begin{array}{l}\text { High blood } \\
\text { pressure }\end{array}$} & yes & $13(72.2)$ & $5(38.5)$ \\
\hline & & no & $5(27.8)$ & $8(61.5)$ \\
\hline & \multirow{2}{*}{ Diabetes } & yes & $8(44.4)$ & $5(38.5)$ \\
\hline & & no & $10(55.6)$ & $8(61.5)$ \\
\hline & \multirow{2}{*}{ Arthritis } & yes & $5(27.8)$ & $8(61.5)$ \\
\hline & & no & $13(72.2)$ & $5(38.5)$ \\
\hline
\end{tabular}


of the 12-week walking program, the experimental group showed a significant improvement in self-management of risk factors of metabolic syndrome $(F=4.61, \mathrm{p}<0.05)$, which may indicate significantly better self-regulation of health in everyday life than in the control group (Table 3).

Table 4 shows that there were some significant differences between the two groups in risk factors of metabolic syndrome on completion of the 12 -week walking program. In terms of the number of risk factors of metabolic syndrome, the total number of risk factors of metabolic syndrome differed significantly between the two groups $(F=7.98, \mathrm{p}<0.01)$, indicating a significantly lower rate of metabolic syndrome in the experimental group than in the control group. In addition, the experimental group reported significantly improved BMI $(F=5.81, \mathrm{p}<0.05)$ and systolic blood pressure $(F=4.16, \mathrm{p}<0.05)$. Group differences in blood sugar, HDL$\mathrm{C}$, diastolic blood pressure, and waist circumference were found not to be significant.

\section{DISCUSSION}

In this study, we conducted a 12 -week walking exercise and health education program for older Korean adults, who showed at least three components of metabolic syndrome. The experimental group showed a significant improvement in self-management and metabolic syndrome symptoms at the end of the 12-week walking program.

The walking exercise and health education were effective at improving self-management of older adults. Few studies have investigated the direct effect of a walking program on older adults' self-management of metabolic syndrome. Chang et al. ${ }^{17)}$ suggested that nurse-led empowerment strategies for hypertensive patients with metabolic syndrome improved metabolic syndrome symptoms and self-management behaviors. In Korea, Lee ${ }^{16)}$ found that a self-care program for hypertensive outpatients improved self-management compliance with diet, exercise, regular medication intake, blood pressure, and stress management. Our present study showed that health education could help the elderly with medical management, promote good food habits, help manage negative emotions, reduce alcohol intake, and reduce smoking. In addition, health education can provide older adults with the necessary knowledge, skills, and confidence to deal with metabolic syndrome-related problems. Considering that older adults' self-management is closely associated with health behavior, it is necessary to incorporate health education in health promotion programs for older adults.

The number of metabolic syndrome risk factors in the experimental group was significantly reduced from $4.00 \pm 0.97$ to $2.33 \pm 0.97$. These findings are consistent with previous studies that have examined the relationship between walking exercise and metabolic syndrome in older adults $^{8,18)}$. Our study confirmed that walking and health education effectively ameliorated the risk factors of metabolic syndrome. Considering that metabolic syndrome is related to the prevalence, onset rate, and mortality rate of diabetes and cardiovascular diseases ${ }^{19)}$, a walking program is recommended for older adults as an effective approach for combating the harmful risk factors of metabolic syndrome.

In this study, after performance of the 12-week walking program, the BMI of the experimental group significantly decreased from $25.97 \mathrm{~kg} / \mathrm{m}^{2}$ to $25.00 \mathrm{~kg} / \mathrm{m}^{2}$. Our results are consistent with a previous study, which reported that a 12-week walking program, plus individual motivational sessions, significantly reduced the BMI of Thai patients ${ }^{20)}$. Musto et al. ${ }^{21)}$ found that an active walking group with a pedometer program showed significant reductions in BMI and systolic blood pressure. These results confirm that walking exercise for older adults is effective at decreasing BMI.

Table 3. Mean group comparisons in score changes in self-management between the pretest and the posttest

\begin{tabular}{ccccc}
\hline & \multicolumn{2}{c}{ Experimental $(\mathrm{n}=18)$} & \multicolumn{2}{c}{ Control $(\mathrm{n}=13)$} \\
& Pre-test & Post-test & Pre-test & Post-test \\
\hline Self-management & $2.46(0.37)$ & $2.65(0.22) *$ & $2.16(0.31)$ & $2.31(0.35)$ \\
\hline Values are expressed as mean $(\mathrm{SD}),{ }^{*} \mathrm{p}<0.05$ & & &
\end{tabular}

Table 4. Mean group comparisons score changes in the numbers of risk factors of metabolic syndrome between the pretest and the posttest

\begin{tabular}{llcccc}
\hline & & \multicolumn{2}{c}{ Experimental $(\mathrm{n}=18)$} & \multicolumn{2}{c}{ Control $(\mathrm{n}=13)$} \\
\cline { 3 - 5 } & & Pre-test & Post-test & Pre-test & Post-test \\
\hline \multirow{4}{*}{ Risk factors } & Total numbers of risk factors & $4.00(0.97)$ & $2.33(0.97) * *$ & $4.15(0.80)$ & $3.30(0.94)$ \\
of metabolic & Blood sugar & $130.50(42.67)$ & $102.50(28.49)$ & $114.31(26.67)$ & $107.30(19.33)$ \\
syndrome & Triglyceride & $44.83(5.19)$ & $54.00(6.87)$ & $45.23(9.10)$ & $54.15(10.99)$ \\
& Systolic blood pressure & $210.38(115.80)$ & $180.88(94.74)$ & $241.76(135.54)$ & $206.31(99.43)$ \\
& Diastolic blood pressure & $157.22(20.80)$ & $136.22(15.97) *$ & $153.84(17.92)$ & $147.00(15.59)$ \\
& BMI & $90.00(17.14)$ & $80.38(13.39)$ & $87.38(9.84)$ & $84.00(11.08)$ \\
& Waist circumference & $25.97(3.69)$ & $25.00(2.52) *$ & $26.60(3.18)$ & $27.37(2.94)$ \\
\hline
\end{tabular}

Values are expressed as mean (SD), ${ }^{*} \mathrm{p}<0.05,{ }^{* *} \mathrm{p}<0.01$ 
In this study, systolic blood pressure significantly decreased in the experimental group after the program, therefore, the walking program can be considered an appropriate exercise for reducing blood pressure. Farinatti ${ }^{22}$ reported that systolic and diastolic blood pressures were reduced by 6 and $9 \mathrm{mmHg}$, respectively, after an aerobic exercise program of 30 minutes walking 3 times a week; however, Stevenson and Topp ${ }^{23)}$ reported that systolic and diastolic blood pressures were not significantly changed after elderly subjects performed a low intensity exercise program for 9 months. This difference is likely due to the selection of study subjects, the length of the exercise program, and the individual characteristics of the elderly subjects.

In this study, there were no significant differences in blood sugar, HDL-C, triglyceride, or waist circumference between the two groups. Although statistically not significant, positive trends in blood sugar and in HDL-C were observed in the exercise group. The walking program was deemed to be not long enough to reduce blood lipid levels or blood sugar levels. Koutroumpi et al. ${ }^{24)}$ suggested that moderate-intensity exercise needs to be performed most days of the week to produce favorable changes in blood cholesterol levels.

To sum up, this study provides new evidence linking walking and health education with metabolic syndrome. For effective secondary prevention, health care providers may use a new strategy and intervention, such as a walking regime and health education for the older adults with metabolic syndrome living in rural areas. In conclusion, a 12-week walking program that combined walking exercise with health education is effective at maintaining good health and ameliorating metabolic syndrome among the elderly. However, it was difficult to distinguish between the effects of walking exercise and health education based on the experimental design of this study. Further studies are needed to identify the independent effects of walking exercise and health education, and the combination effects of walking exercise and health education on metabolic syndrome in the elderly.

\section{ACKNOWLEDGEMENT}

This work was financially supported by the research funding of Namseoul University in 2013.

\section{REFERENCES}

1) Grundy SM, Brewer HB, Jr Cleema JI, et al.: Definition of metabolic syndrome: report of the National Heart, Lung, and Blood Institute/ American Heart Association conference on scientific issues related to definition. Circulation, 2004, 109: 433-438.

2) Mozumdar A, Liguori G: Persistent increase of prevalence of metabolic syndrome among U.S. adults: NHANES III to NHANES 1999-2006. Diabetes Care, 2011, 34: 216-219. [Medline] [CrossRef]
3) Byrne CD, Wild SH: Diabetes care needs evidence based interventions to reduce risk of vascular disease. BMJ, 2000, 320: 1554-1555. [Medline] [CrossRef]

4) Song MS, Yoo YK, Choi CH, et al.: Effects of Nordic Walking on body composition, muscle strength, and lipid profile in elderly women. ANR, 7: 1-7. http://dx.doi.org/10.1016/j.anr.2012.11.001.

5) Ministry of Health and Welfare and Korea Centers for Disease Control and Prevention: Korean National Health and Nutrition Examination Survey in 2009. 2010. http://knhanes.cdc.go.kr (Accessed Apr. 8, 2013)

6) Eyler AA, Brownson RC, Bacak SJ, et al.: The epidemiology of walking for physical activity in the United States. Med Sci Sports Exerc, 2003, 35: 1529-1536. [Medline] [CrossRef]

7) Nuri R, Kordi MR, Moghaddasi M, et al.: Effect of combination exercise training on metabolic syndrome parameters in postmenopausal women with breast cancer. J Cancer Res Ther, 2012, 8: 238-242. [Medline] [CrossRef]

8) Brien SE, Katzmarzyk PT: Physical activity and the metabolic syndrome in Canada. Appl Physiol Nutr Metab, 2006, 31: 40-47. [Medline] [CrossRef]

9) Park JR: The effect of dance sports on the risk factor and physical function in metabolic syndrome elderly people. Unpublished master dissertation, Seoul National University, 2004.

10) Karst K: The metabolic syndrome program: how to lose weight, beat heart disease, stop insulin resistance and more. John Wiley \& Sons, 2006.

11) Riegel B, Carlson B, Glaser D: Development and testing of a clinical too measuring self-management of heart failure. Heart Lung, 2000, 29: 4-15. [Medline] [CrossRef]

12) Effing T, Monninkhof EM, van der Valk PD, et al.: Self-management education for patients with chronic obstructive pulmonary disease. Cochrane Database Syst Rev, 2007, 17: CD002990. [Medline]

13) Lorig KR, Holman HR: Self-management education: history, definition, outcomes, and mechanisms. Ann Behav Med, 2003, 26: 1-7. [Medline] [CrossRef]

14) Lakka TA, Laaksonen DE: Physical activity in prevention and treatment of the metabolic syndrome. Appl Physiol Nutr Metab, 2007, 32: 76-88. [Medline] [CrossRef]

15) Kim YR, Gu HM, Cho SS: A study on current status of physical activity and plan for improving sport participation of the aged. Kor J Sports Sci, 2004, 15: 84-98.

16) Lee OJ: The effect of self care program for hypertension outpatients in a general hospital, Unpublished master's thesis, Chonbuk National University, 2009.

17) Chang AK, Fritschi C, Kim MJ: Nurse-led empowerment strategies for hypertensive patients with metabolic syndrome. Contemp Nurse, 2012, 42: 118-128 [CrossRef]. [Medline]

18) Katzmarzyk PT, Leon AS, Wilmore JH, et al.: Targeting the metabolic syndrome with exercise: evidence from the HERITAGE Family Study. Med Sci Sports Exerc, 2003, 35: 1703-1709. [Medline] [CrossRef]

19) Laaksonen DE, Lakka HM, Niskanen LK, et al.: Metabolic syndrome and development of diabetes mellitus: application and validation of recently suggested definitions of the metabolic syndrome in a prospective cohort study. Am J Epidemiol, 2002, 156: 1070-1077. [Medline] [CrossRef]

20) Methapatara W, Srisurapanont M: Pedometer walking plus motivational interviewing program for Thai schizophrenic patients with obesity or overweight: a 12-week, randomized, controlled trial. Psychiatry Clin Neurosci, 2011, 65: 374-380. [Medline] [CrossRef]

21) Musto A, Jacobs K, Nash M, et al.: The effects of an incremental approach to $10,000 \mathrm{steps} /$ day on metabolic syndrome components in sedentary overweight women. J Phys Act Health, 2010, 7: 737-745. [Medline]

22) Farinatti PT, Oliveira RB, Pinto VL, et al.: Home exercise program: short term effects on physical aptitude and blood pressure in hypertensive individuals. Arq Bras Cardiol, 2005, 84: 473-479. [Medline] [CrossRef]

23) Stevenson JS, Topp R: Effects of moderate and low intensity long-term exercise by older adults. Res Nurs Health, 1990, 13: 209-218. [Medline] [CrossRef]

24) Koutroumpi M, Pitsavos C, Stefanadis C: The role of exercise in cardiovascular rehabilitation: a review. Acta Cardiol, 2008, 63: 73-79. [Medline] [CrossRef] 